\title{
PERLAWANAN PETANI DI TANAH PARTIKELIR TANJOENG OOST BATAVIA TAHUN 1916
}

\author{
THE PEASANT STRUGGLE IN PRIVATE LAND \\ OF TANJOENG OOST BATAVIA IN 1916 \\ Iim Imadudin \\ Balai Pelestarian Nilai Budaya Bandung \\ Jln. Cinambo No.136 Ujungberung-Bandung 42094 \\ e-mail:iim.imadudin@yahoo.com

\begin{abstract}
Abstrak
Sepanjang abad XIX dan awal abad XX terjadi banyak pergolakan di Nusantara. Salah satu di antaranya terjadi di tanah partikelir Tanjoeng Oost Batavia. Perlawanan Entong Gendut di Tanjoeng Oost Batavia pada tahun 1916 berkaitan dengan sistem tanah partikelir di daerah tersebut. Peristiwa tersebut mencerminkan terjadinya ketegangan horizontal maupun vertikal. Di tanah partikelir Tanjoeng Oost Batavia, tuan tanah mengeksploitasi tanah dan petani yang hidup di wilayahnya. Sejak diberlakukannya UU Agraria 1870, pemilik modal menjadikan tanah sebagai alat produksi. Oleh karena itu, tidak ada lagi hubungan yang bersifat mutualistis, namun bergeser pada aspek komersialisasi pertanian. Para petani yang bekerja pada perkebunan memperoleh perlakuan yang sewenang-wenang. Peraturan tanah partikelir sering berubah-ubah, pajak tidak tetap, dan pemberlakuan kerja wajib. Dalam kondisi demikian, timbullah gerakan perlawanan yang dimotivasi oleh semangat keagamaan. Para pengikut Entong Gendut menganggap dirinya sebagai ratu adil. Penelitian yang mempergunakan metode sejarah ini bertujuan mengungkap perlawanan Entong Gendut dan respons pemerintah kolonial terhadap gerakan petani di tanah partikelir Tanjoeng Oost. Kajian mengenai resistensi petani era kolonial dalam konteks tanah partikelir penting sebagai bahan refleksi sejarah. Meski pernyataan sejarah berulang sekarang dipertanyakan, namun terdapat kemiripan pola-pola protes sosial dari dulu hingga kini
\end{abstract}

Kata kunci: perlawanan petani, tanah partikelir, Batavia.

\begin{abstract}
There are a lot of upheaval in the archipelago throughout the nineteenth century and early twentieth century. One of them are occurred on private land Tanjoeng Oost Batavia. Entong Geendut resistance in Tanjoeng Oost Batavia in 1916 relating to the system of private land in the area. These events reflect the horizontal and vertical tension. In the private land of Tanjoeng Oost Batavia, landlords exploit the land and the farmers who live in the territory. Since the enactment of the Agrarian Law, 1870, owners of capital make the soil as a production tool. Therefore, there is no relationship of mutualism, but shifts in aspects of agricultural commercialization._The peasants who worked on the plantation earned arbitrary treatment. Regulation of private land ever-changing, taxes are not fixed, and the imposition of compulsory labor. In such conditions, there was a resistance movement motivated by religious fervor. The fellow of Entong Gendut consider themselves to be fair queen. The research method is historical method and try to reveal the Entong Gendut struggle against the colonial government's as a response to the peasant movement in Oost Tanjoeng private land. The study of peasant resistance in colonial era important in the context of private land as a reflection of history. Although history repeats itself now as a questionable statements, but there are similar patterns of social protests of the past until now.
\end{abstract}

Keywords: peasant struggle, private land, Batavia. 


\section{A. PENDAHULUAN}

Heraclitus, filsuf Yunani menyatakan bahwa di dunia ini tidak ada yang tidak berubah. Semua berubah, kecuali perubahan itu sendiri. ${ }^{1}$ Perubahan merupakan keharusan sejarah (historical necessity) yang terus ada dalam kehidupan manusia. Situasi konflik atau antagonisme sering menjadi bagian yang dominan mewarnai jalannya perubahan. Ada golongan sosial yang berupaya mempertahankan diri melawan kelompok yang berjuang melakukan pembaharuan (Kartodirdjo, 1983: viii).

Antagonisme biasanya dilatarbelakangi stagnasi dan rasa jenuh yang muncul. Pada tahap awal gerakan massa mendapat dukungan terbesar dari kelompok orang bosan (Hoffer, 1988: 53). Akhirnya, timbullah perubahan yang disengaja sebagai anteseden dari keadaan stagnan.

Pemicu dari perubahan itu dapat berdimensi ekonomi, politik, dan sebagainya. Demikian pula, rasa frustasi dapat juga merupakan reaksi atas terjadinya suatu perubahan. Rasa bosan, frustasi, dan ketertindasan merupakan lahan yang subur bagi tumbuhnya usaha melakukan perubahan. Namun pertanyaan yang tak kalah pentingnya adalah apakah perubahan itu, sebagai dikonsepsikan Hegel dalam dialektika historis-nya, bergerak secara regresif menuju keadaan yang lebih buruk dari sebelumnya atau lebih baik dalam artian progresif (Surbakti, 2010: 299).

Pantun di bawah ini merupakan refleksi perjuangan ke arah perubahan. Perjuangan tersebut dapat berhasil, dapat

\footnotetext{
${ }^{1}$ Dalam bahasa Inggris dikatakan "nothing endures but change”. Kutipan ini berasal dari tulisan-tulisan Heraclitus (535-475 SM) yang dikumpulkan oleh Daegenes Laertius dan diterjemahkan ke dalam bahasa Inggris C.D. Yonge. Bagi Heraklitus, perubahan itu riil, dan stabilitas itu ilusi. "Change is the leading upward, and the road leading downward, and the whole world exists according to it" (Ishwara, 2011: 9).
}

pula mengalami kegagalan tergantung cara memaknainya.

\section{Ular kadut mati di kobak Burung betet makanin laron Entong Gendut mati ditembak Orang Condet pada buron}

Sebait pantun di atas menyimpan kenangan kolektif tentang kisah perjuangan Entong Gendut dari Condet. Pantun ini menyampaikan pesan heroisme Entong Gendut dari generasi ke generasi secara berkesinambungan. Tidak hanya pantun, reproduksi nilai-nilai moral Entong Gendut disampaikan dalam seni lenong, palang pintu pada pernikahan adat Betawi, dan cerita rakyat.

Perlawanan Entong Gendut harus dilihat dalam situasi politik awal abad ke20. Pergolakan di tanah partikelir di penghujung abad ke-19 dan permulaan awal abad ke-20 merupakan gejala historis dari masyarakat petani pribumi. Pemicu dari semua perlawanan atau kerusuhan tersebut sebagian besar merupakan konsekuensi logis dari beratnya tuntutan pajak dan kerja rodi terhadap petani. Itulah sebabnya, kerusuhan yang terjadi di tanah disebut juga kerusuhan cuke, yang berasosiasi dengan nama jenis pungutan pajak yang membebani petani (Poesponegoro dan Nugroho Notosusanto, 2008: 400).

Umumnya, ciri khas gerakan perlawanan sosial tersebut cenderung bermotifkan perasaan dendam yang bersifat milenaristis atau mesianistis (Ekadjati et al., 1990: 139).

Penolakan atas pajak memang merupakan pemberontakan khas petani Asia Tenggara. Cirinya-cirinya ada penegasan ekonomi lokal dari sejumlah pemberlakuan pajak yang baru (Scott, 1993: 127).

Kemunculan tanah-tanah partikelir dimulai oleh praktik penjualan tanah kepada swasta pada masa VOC (16021799). Kebijakan tersebut terus berlangsung hingga pemerintahan Gubernur Jenderal Herman Willem Daendels (1808-1811) dan Letnan 
Gubernur Thomas Stamford Raffles (18111816). Kemudian, berlanjut hingga tahun 1820-an.

Tanah-tanah partikelir terdapat di sekitar Batavia, Bogor, Banten, Karawang, Cirebon, Semarang dan Surabaya. Motif dari penyerahan tanah-tanah itu beragam. Sebagian besar bermotifkan kepentingan politis saat penyerahan tanah dengan status tanah partikelir oleh VOC. Penyerahan tersebut dianggap sebagai hadiah VOC terhadap orang-orang yang dianggap berjasa menjaga ketenteraman dan ketertiban di wilayah sekitar Batavia. Mereka di antaranya adalah mantan pegawai atau perwira VOC dan kepala penduduk pribumi.

Praktik penjualan tanah partikelir tidak hanya berupa penyerahan tanah, melainkan penduduk yang tinggal di tanah tersebut. Para pemilik tanah menguasai tanah secara mutlak dalam jangka waktu yang lama. Para tuan tanah mendapat hakhak istimewa seperti yang dimiliki pemerintah (hak fiskal) dan kepolisian (keamanan).

Dengan hak istimewa yang dimilikinya, para tuan tanah berhak menuntut sebagian hasil produksi tanah garapan para petani. Selain itu, penyerahan tenaga kerja bagi keperluan pribadi tuan tanah menjadi wajib, antara lain memetik buah, menggarap dan memelihara tanaman atau mengangkut barang dari satu tempat ke tempat lainnya.

Para tuan tanah dapat dengan leluasa melakukan eksploitasi tanah miliknya. Kekuasaaan tanpa batas itu membuat mereka sering melakukan kecurangankecurangan. Beberapa di antara kecurangan itu, seperti memanipulasi reglemen dan kontrak kerja. Pemerintah sebenarnya tidak menutup mata terhadap praktik kecurangan seperti itu. Upaya perbaikan yang dilakukan, di antaranya melarang tuan tanah menerima sepersepuluh dari hasil tanah atau memungut penyerahan tenaga kerja yang berat. Akan tetapi, kontrol pemerintah terhadap tuan tanah memang sangat lemah.
Pemerintah tidak dapat berbuat apa-apa ketika berbagai pelanggaran dilakukan tuan tanah.

Tindakan tuan tanah yang melampaui batas menimbulkan kegelisahan dan frustasi di kalangan para petani. Berbagai aksi protes terjadi di beberapa tanah partikelir seperti di Batavia dan Cirebon (1816), Cikande Udik (1845), Ciomas (1886) dan Ciampea (1892). Ketegangan semakin meningkat, terutama di paruh pertama abad ke-20. Salah satu di antara gerakan yang cukup menonjol terjadi tanah partikelir Tanjoeng Oost Batavia pada tahun 1916 (Koloniaal Verslag, 1916).

Kehidupan di tanah partikelir Tanjoeng Oost bagi penduduk Condet dirasakan sangat berat. Penduduk yang bekerja di tanah partikelir harus menggarap lahan dan kebun tuan tanah dalam kondisi tertekan. Tentu saja kebijakan yang paling berat bagi penduduk adalah kewajiban petani membayar pajak sewa tanah 25 sen setiap minggunya. Bila tidak mampu membayar, mereka wajib melakukan kerja paksa selama seminggu menggarap sawah dan kebun tuan tanah atau aparat kolonial.

Dalam situasi seperti itu, timbul reaksi dari penduduk Condet untuk melawan tindakan sewenang-wenang tuan tanah. Ekspresi dari ketertekanan tersebut berupa rasa amarah, kebencian, bahkan perlawanan fisik. Salah satu di antaranya adalah perlawanan Entong Gendut, pendekar perguruan Silat Silau Macan di daerah Condet. Ia dikenal juga dengan Haji Entong Gendut. Ia memobilisasi penduduk Condet agar melawan sistem kolonial yang menindas.

Kajian mengenai perlawanan Entong Gendut setidaknya telah menghasilkan dua skripsi. Abd. Nashir (1987) menulis Kerusuhan Petani di Condet Tahun 1916. Eksploitasi tuan tanah secara berlebihan menimbulkan kebencian penduduk. Penulis juga menekankan peran pihak-pihak luar masyarakat Condet yang ikut 
mematangkan perlawanan. Yayi Ningsih (2007) menulis Gerakan Protes di Tanjung Timur Dipimpin oleh Entong Gendut Tahun 1916. Penulis mengaitkan gerakan protes dengan sistem tanah di wilayah partikelir yang menimbulkan kebenciaan hingga memunculkan sosok Entong Gendut sebagai ratu adil.

Gerakan perlawanan sering dilakukan masyarakat petani dalam sistem politik yang berbeda-beda. Sejak zaman kolonial hingga kemerdekaan, konflik di lingkungan masyarakat petani sering terjadi. Peristiwa sejarah memang hanya terjadi sekali (einmalig), tetapi terdapat kemungkinan kesamaan pola dan struktur yang kondusif bagi munculnya konflik di masyarakat. Ilmu sejarah dapat membantu menangani konflik melalui pendekatan genetis, komparatif, dan paralelisme historis. Artikel ini berupaya memberi gambaran tentang latar belakang, sebab yang lebih dekat dengan peristiwa, dan trigger (pemicu) dari gerakan perlawanan Entong Gendut di tanah partikelir Tanjoeng Oost Batavia.

\section{B. METODE PENELITIAN}

Kajian artikel ini menggunakan metode sejarah, yang terdiri dari empat tahapan. Tahap pertama, heuristik atau upaya pencarian sumber terhadap objek yang diteliti. Data tersebut didapat melalui penelitian di perpustakaan (library research). Buku-buku penunjang atau literatur diperoleh melalui studi pustaka di perpustakaan BPNB Bandung Perpustakaan Cisral Unpad, Perpustakaan Wilayah Jawa Barat, dan Arsip Nasional. Penelitian ini banyak memanfaatkan arsip Memori Serah Jabatan yang diterbitkan Arsip Nasional RI.

Tahap selanjutnya adalah tahap kritik, dilakukan dengan membuat perbandingan dari beberapa sumber atau dengan membandingkan dengan faktafakta yang ada sebelumnya. Kritik dengan dasar sumber yang ada akan menguji apakah gerakan sosial lebih bermotifkan ekonomi ataukah politik. Tahap ketiga adalah tahap interpretasi, tahap menafsirkan fakta yang membutuhkan kerangka dan dasar pengertian objek penelitian, dan dilakukan dengan bantuan konsep dan teori. Tahap terakhir adalah penulisan sejarah, fakta-fakta yang telah diinterpretasikan dituliskan dalam suatu penulisan yang sistematis dan kronologis.

Analisis artikel ini menggunakan

teori Perilaku Kolektif (Theory of Collective Behavioral) yang diperkenalkan Neil J. Smelser (Jung, 1966: 318-320). Smelser memerinci perilaku kolektif sebagai mobilisasi atas dasar suatu keyakinan (belief) yang meredefinisikan kembali aksi-aksi sosial (social action). Sementara itu, perilaku kolektif, menurut Blumaer, didefinisikan sebagai suatu gerakan sosial (social movement) yang dilakukan secara kolektif untuk menata kehidupan yang baru. Dasar gerakan sosial adalah the basic frustration (Zubir, 2002: 40).

Setiap aksi sosial membutuhkan sejumlah determinan, yaitu kondisi yang diperlukan (necessary condition) yang menciptakan suasana atau kondisi yang cukup (sufficient condition) bagi tumbuhnya aksi perlawanan (Swartz, 1997: 1).

Adapun determinan yang terdapat dalam teori Perilaku Kolektif sebagai berikut:

1. Structural condusiveness (kekondusifan struktural): suasana atau iklim yang memungkinkan dari struktur sosial budaya masyarakat untuk melakukan aksi;

2. Structural strain (ketegangan struktural): ketegangan struktural ini dapat terjadi apabila sesuatu yang diharapkan tidak sesuai dengan kenyataan, bahkan lebih jauh lagi kenyataan-kenyataan yang muncul justru berbalik menjadi ancaman;

3. Growth and spread of generalized belief (pertumbuhan dan penyebaran keyakinan yang dianut);

4. Precipitant factors (faktor pencetus): struktural yang kondusif, ketegangan dan kepercayaan belum menghasilkan 
sebuah episode, kecuali sudah ada faktor pencetus. Faktor pencetus ini adalah sesuatu yang dramatis;

5. Mobilization of participants for action (mobilisasi untuk melakukan aksi): pemimpin, kepanikan, agitasi untuk reformasi;

6. The operation of social control (berjalannya kontrol sosial): semacam kontrol sosial, determinan yang mencegah, mengganggu, membelokkan dan merintangi gejolak itu dengan cara mencegah terjadinya episode gejolak sosial dan mobilisasi alat-alat negara segera setelah episode gejolak sosial mulai terjadi (Lubis, 2000: 64).

Untuk menjelaskan kepemimpinan kharismatis digunakan konsep "karisma". Max Weber menjabarkan karisma sebagai "mutu tertentu yang melekat pada kepribadian seseorang yang menyebabkan ia dianggap luar biasa dan diperlakukan orang sebagai seseorang yang dikaruniai kekuatan supranatural (gaib), seorang manusia super atau setidak-tidaknya mempunyai kekuatan atau kualitas sangat istimewa" (Burke, 200:133).

Dalam konteks gerakan milenaristis, para pengikut meyakini bahwa dalam waktu yang tidak lama lagi akan lahirnya masyarakat baru yang akan melenyapkan segala kesengsaraan (Korver, 1982: 73). Gerakan protes yang bernuansa keagamaan juga sering bertipe nativisme, yaitu gejala yang menunjukkan adanya kebencian yang kuat terhadap penguasa asing yang dianggap bertanggung jawab terhadap situasi yang terjadi (Korver, 1982: 74-75).

Tipe gerakan sosial terbagi menjadi dua, yaitu gerakan yang memulai suatu proses perubahan dan gerakan yang merupakan reaksi atas perubahan yang terjadi. Kebanyakan gerakan sosial yang terjadi bertipe "reaktif", yaitu gerakan rakyat yang memprotes perubahan ekonomi atau sosial yang mengancam cara hidup yang berlaku (Frederick \& Soeri Soeroto, 1984: 135). Bagi petani, perlawanan bertujuan tidak untuk mengubah keadaan yang sedang terjadi, apalagi menumbangkan sistem dominasi. Mereka lebih berkepentingan untuk dapat bertahan dalam sistem (Scott, 1993: xiv).

Untuk memahami pola hubungan petani dan elit digunakan pula konsep Patron-Klien. Antropolog umumnya mendefinisikan patron-klien sebagai:

......an exchange relationship between roles- may be defined as special case of dyadic (two-person) ties involving a largely instrumental friendship in which an individual of higher socioeconomic status (patron) uses his own influence and resources to provide protection or benefits, or both, for a person of lower status (client) who, for his part, reciprocates by offering general support and assistance including personal services, to the patron.

.....hubungan pertukaran antara dua orang yang melibatkan sebagian besar peran dalam persahabatan-yang status sosial ekonomi individu atau lebih tinggi (patron) menggunakan pengaruhnya sendiri dan sumber daya untuk perlindungan, pemeliharaan atau manfaat, atau keduanya, untuk orang dari status yang lebih rendah (klien) yang, pada bagiannya, membalasnya dengan menawarkan dukungan umum dan pribadi bantuan-termasuk, untuk perlindungan. $^{2}$

\section{HASIL DAN BAHASAN \\ 1.Riwayat Tanah Partikelir Tanjoeng O ost Batavia}

Pemilik pertama kawasan tanah partikelir Tanjoeng Oost (Tanjoeng Timur) adalah Pieter van de Velde dari Amersfoort, Belanda. Pascapemberontakan Cina 1740, van de Velde mengusai tanah-tanah milik Kapten Ni Hu-Kong. Lokasinya berada di selatan Meester Cornelis sebelah timur sungai Ciliwung. Pemilikannya atas tanah terus bertambah dengan tanah-tanah lainnya yang dibelinya pada tahun 1750. Maka muncullah Tanah Partikelir Tanjoeng Oost.

\footnotetext{
${ }^{2}$ http://chenry.webhost.utexas.edu/public_html/ AUC/Scott-1972-clientelism.pdf
} 
Pada tahun 1750 van de Velde membangun villa sebagai tempat peristirahatan (Landhuis). Letaknya yang yang berada di pinggiran pusat kota Batavia, membuat kawasan Tanjoeng Timur tempat yang cocok untuk peristirahatan dan lahan pertanian. Pada mulanya wilayah ini masih berupa lahan kosong yang ditumbuhi pepohonan besar.

Adrian Jubels menjadi pemilik kedua. Selanjutnya, pada tahun 1763, Jacobus Johannes Craan membeli Tanah Tanjoeng Oost. Ia merenovasi gedung peristirahatan dengan dekorasi berlanggam Lodewijk XV, dengan hiasan- hiasan Cina. Kemudian Tanjoeng Oost dibeli Willem Vincent Helvetius van Riemsdjik. Ia adalah putra Gubernur Jendral Jeremies van Riemsdjik (1775-1777).

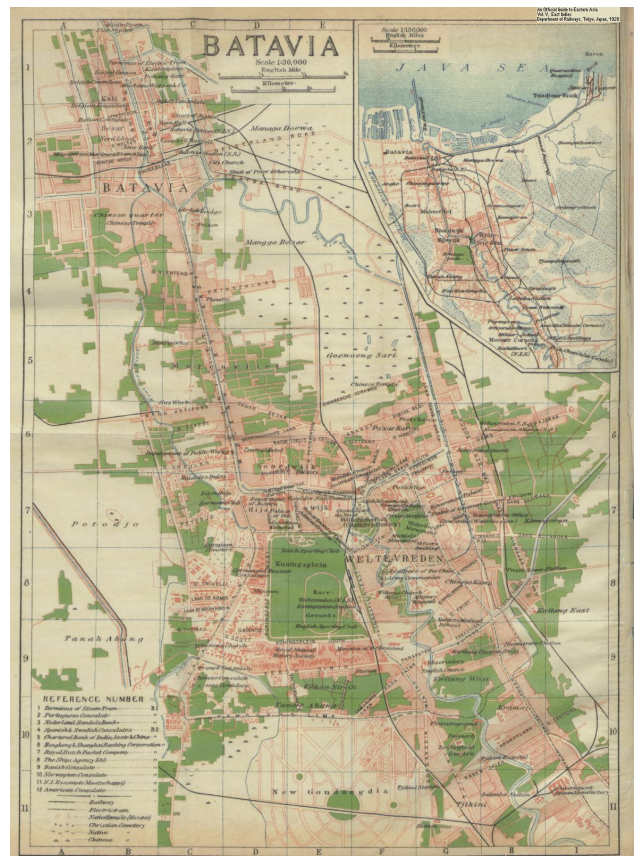

Gambar 1. Kawasan Batavia tahun 1920 Sumber:

http://niehorster.orbat.com/016_netherlands/ma ps/Batavia\%201920.gif

Sejak usia muda, Willem Vincent Helvetius sudah menduduki jabatan strategis. Pada usia 17 tahun sudah diangkat menjadi administratur P. Onrust. Ia mampu memanfaatkan kedudukan ayahnya sebagai Gubernur Jenderal, sehingga kekayaan dan kekuasaannya terus meningkat. Sampai penghujung abad ke18 , pemilikan tanahnya tersebar mulai dari Tanahabang, Cibinong, Cimanggis, Ciampea, Cibungbulan, Sadeng, dan Tanjoeng Oost.

Tanah partikelir Tanjoeng Timur mengalami perkembangan yang sangat pesat saat dikelola oleh Daniel Cornelius Helvetius. Ia secara intensif mampu mengembangkan sektor pertanian dan peternakan. Komoditi tanah Tanjoeng Oost dikenal oleh masyarakat luas di Batavia.

Pengelolaan tanah partikelir dilanjutkan Tjalling Ament, yang berasal dari Kota Dokkum, Belanda Utara. Ament menikahi putri Daniel Cornelius yang bernama Dina Cornelia. Ament mengembangkan produksi pertanian dan peternakan. Pada pertengahan abad ke-19, produksi susu peternakan Tanjoeng Timur sangat terkenal di wilayah Batavia. Tanah partikelir Tanjoeng Oost juga menghasilkan kopi dan sereholie. Pada tahun 1914 menghasilkan 60 pikul, sedangkan tahun 1915 ada 75 pikul (Koloniaal verslag 1916).

Tabel 1

Komoditi Kopi Tanah Partikelir di Batavia

\begin{tabular}{l|c|c}
\hline Tanah Partikelir & $\begin{array}{l}\text { Jumlah } \\
\text { (Pikul) }\end{array}$ & \\
\hline BANTAM & 27 & 16 \\
Tjikande Ilir & & \\
\hline BATAVIA & 2 & - \\
Pangkalan................ & 60 & 75 \\
Tjiboeboer................. & 60 & 75 \\
Tandjoeng Oost......... & 13 & 9 \\
Kranggan................... & & \\
Tandjoeng-West of & \\
\hline
\end{tabular}




\begin{tabular}{|c|c|c|}
\hline 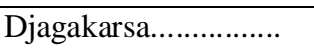 & & \\
\hline $\begin{array}{l}\text { Kampong Makasser, } \\
\text { Hermendal en Tanah } \\
\text { Toewaratoes.................. }\end{array}$ & 10 & 8 \\
\hline $\begin{array}{l}\text { Tjakoeng en Pondok } \\
\text { Klapa............................. }\end{array}$ & 05 & - \\
\hline Lengkong oost I & 2 & - \\
\hline $\begin{array}{l}\text { Serpang, Lengkong } \\
\text { Tjisaroek en Lengkong }\end{array}$ & & \\
\hline Sempora.............................. & 5 & - \\
\hline & 10 & - \\
\hline
\end{tabular}

Sumber: Koloniaal Verslag, 1916

Sampai meletusnya Perang Dunia, kawasan tanah Tanjoeng Oost diwariskan secara turun-temurun pada keturunan Vincent Helvetius van Riemsdij. Sekarang kawasan tersebut dikenal dengan Kampung Gedong. Sebutan Kampung Gedong merujuk pada sebuah gedung peristirahatan (landhuis) tuan tanah Tanjoeng Oost. Gedung tersebut memiliki halaman yang luas. Pemilik terdahulu memberi nama Groeneveld, yang berarti lapangan hijau. Pemandangan di sekelilingnya sangat asri. Sekarang menjadi perempatan Pasar Rebo, Jl. Raya Bogor. Di sisi jalan ditanami pahon asem (Tamarindus indica).

\section{Kebijakan Tanah Partikelir}

Keberadaan tanah partikelir memiliki sejarah panjang. Namun, titik tolak perkembangan tanah partikelir bermula ketika tahun 1870 diterapkan "politik pintu terbuka" (open door policy) di Hindia Belanda. Para pengusaha swasta asing memiliki peluang yang lebih besar untuk menanamkan modalnya di bidang perkebunan. Dasar hukum dari sistem liberal ini adalah Undang-Undang De Waal, yaitu Undang-Undang Agraria dan Undang-Undang Gula. Undang-Undang Agraria (de Agrarische Wet) diatur dalam Staatsblad No. 71 tanggal 9 April 1870.
Para pengusaha swasta Belanda maupun swasta Eropa lainnya mendirikan perkebunan-perkebunan kopi, teh, gula, dan kina. Pembukaan perkebunanperkebunan besar ini dipayungi secara hukum oleh Undang-Undang Agraria (Agrarische Wet) yang dikeluarkan pada tahun 1870. Pada suatu pihak UndangUndang Agraria membuka peluang bagi orang-orang asing untuk menyewa tanah dari rakyat Indonesia (Poesponegoro, 1992: 118).

Implementasi Agrarische Wet menimbulkan konflik sosial di tanah partikelir. Lahirlah tuan-tuan tanah partikelir (particuliere landerijen) yang sangat berkuasa.

Tanah partikelir menjadi "mesin uang" bagi tuan tanah berkebangsaan Eropa dan Cina. Sementara itu, bagi petani tanah partikelir menambah beban kaum pribumi, terutama petani-penyewa dan buruh.

Sebenarnya pemerintah sudah membuat "aturan main" di tanah partikelir. Dalam Staatsblad No. 19 tanggal 28 Pebruari 1836 dikemukakan hak-hak pemerintah, tuan tanah, dan penduduk sebagai berikut:

a. Hak-hak Pemerintah

1. Memelihara ketertiban dan keamanan;

2. Melindungi keselamatan penduduk dari ancaman dan bahaya yang mengancam pemerintah;

3. Menguasai jalan-jalan raja, jembatan-jembatan, dam-dam, terusanterusan dan semua pekerjaan untuk kepentingan umum di tanah dan air; dan

4. Kedaulatan atas tanah $P$ en $T$ tetap berada di tangan pemerintah pusat.

b. Hak-hak dan Wewenang Tuan Tanah

1. Memungut hasil panen atau penghasilan dari tanah yang digarap oleh penduduk atau yang sekiranya dapat menghasilkan, seperti tanahtanah gundul, hutan-hutan, hutan bambu; dan 
2. Mempekerjakan penduduk laki-laki yang berumur antara 14-50 tahun selama satu hari pada tiap-tiap minggu, dengan memberi makan yang cukup untuk mengerjakan pembuatan atau perbaikan jalan, menggali saluran-saluran air, memotong rumput, membajak tanah, mengangkut barang-barang di rumah tinggal atau gudang.

c. Hak-hak dan Kewajiban Penduduk

1. Menggembala hewan, mengambil kayu untuk keperluan sehari-hari dengan syarat tidak untuk dijual;

2. Mengangkut bagian dari hasil tanahnya ke gudang tuan tanah tanpa dibayar asal saja gudang-gudang itu berada dalam daerah tanah itu sendiri.

3. Penduduk yang disuruh oleh tuan tanah untuk mengantarkan surat, mengangkut barang-barang dan lainlain harus mendapat upah yang setimpal.

Peraturan pemerintah tersebut memang secara eksplisit mencantumkan sanksi terhadap tuan tanah yang bertindak melebihi aturan yang ditetapkan. Para pelanggar dapat dituntut di muka hukum (pengadilan). Di atas kertas, hak-hak penduduk pribumi dilindungi secara hukum dalam memanfaatkan tanah-tanah untuk keperluan kehidupan sehari-hari.

Akan tetapi, pada kenyataannya aturan tersebut dapat diibaratkan "tumpul ke atas, tajam ke bawah". Tuan tanah partikelir menjelma menjadi "raja-raja" baru. Para pembeli tanah mendapat hak pertuanan (heerlijke rechten) dan hak kenegaraan (overheidrechten). Dengan demikian, para pemilik tanah dapat mengatur tanah dan penduduk yang tinggal di tanah tersebut sesuai dengan keinginannya. Para pemilik berhak mendapat bagian dari hasil panen padi, palawija, buah-buahan, peternakan ikan, dan sebagainya (Broersma, tt: 2). Kenyataan ini membuat status tanah partikelir seolah-olah telah menjadi "negara kecil" dalam negara (Staatjes binnen de Staat) (Effendhie, 2007: 13).

Di tanah partikelir, elit pribumi seperti demang, asisten wedana, dan cutak (camat tuan tanah) bekerja untuk kepentingan tuan tanah. Demang dan para pembantunya bertugas memungut cukai dari penduduk yang menetap di daerah yang berada di bawah pengawasannya (Asdi et al, 39: 2007). Sementara itu, demang lebih berperan sebagai pegawai tanah partikelir (Disbudpar Subang, 2002: 40).

Pada permulaan abad ke-20, serangkaian gelombang kerusuhan meluas di berbagai tanah partikelir, antara Ciomas, Slipi, Cakung, dan Surabaya. Aksi protes dipicu oleh persoalan yang sama, yakni kegagalan pembayaran sewa atau pajak, maupun penebusan kerja wajib. Akibatnya, petani yang bangkrut. Harta mereka dirampas, dijual, bahkan dibakar. Berdasarkan aturan baru tentang tanah partikelir, para tuan tanah diperkenankan mengadili para petani yang tidak mampu membayar pajak (Poesponegoro, 1992: 294).

Situasi yang makin kondusif untuk terjadinya gerakan sosial semakin matang ketika ada kebijakan baru tentang tanah partikelir tahun 1912. Kebijakan tersebut memberikan peluang bagi para tuan tanah untuk menindak petani-petani yang tidak dapat membayar pajak melalui pengadilan. Pada tahun 1913 pengadilan menangani 2.000 perkara kegagalan petani dalam membayar sewa atau pajak pekarangan atau pun penebusan pekerjaan kompeni. Selanjutnya, ada 500 perkara di tahun 1914, dan 300 perkara tahun 1915. Eksekusi putusan pengadilan mengakibatkan petani mengalami kebangkrutan. Harta milik petani disita, dijual, atau dibakar. Selain eksekusi pengadilan, tuan tanah menaikkan pungutan pajak. Pada gilirannya hal tersebut menciptakan rasa dendam dan kebencian yang semakin dalam. 
Beberapa kejadian menjadi riak-riak kecil yang terus memanas. Pada tanggal 14 Mei 1916, penduduk kampung yang bernama Taba dari desa Batu Ampar diadili di Landraad (pengadilan distrik) Meester Cornelis (Jatinegara). Berdasarkan vonis Landraad van Meester Cornelis ddo 14 November 1914 No 4693/1913, Taba wajib membayar sebesar $f 7,20 \quad(7,20$ gulden) dan ongkos perkaranya (ANRI, 1981: 52).

Pada tanggal 15 Maret 1916, pengadilan memberikan tenggat waktu pada Taba agar segera membayar. Bila tidak mampu membayar, pihak yang berwajib akan menyita barang dan menjualnya. Situasi semakin memanas. Penduduk menuding para kepala setempat mengabdi pada kepentingan orang Kristen, karena mereka sama sekali tidak mempertimbangkan penduduk yang miskin. Oleh karena itu, dalam pandangan penduduk, mereka harus dibunuh.

Namun, eksekusi tetap dilanjutkan. para petugas dipimpin Asisten Wedana Pasar Rebo dan mandor Piroen tetap mendatangi rumah Taba pada tanggal 7 Maret 1916 (Pranoto, 2010: 153). Mereka bermaksud menghukum kegagalan Taba membayar sewa tanah. Saat itu penduduk berkumpul dalam posisi bersembunyi di kebun salak Djaimin, yang letaknya hanya sepelemparan batu dari rumah Taba (ANRI, 1981: xl).

Massa yang berjumlah 50 orang berupaya mencegah petugas yang akan melakukan eksekusi. Entong Gendut berada di antara kerumunan massa. Situasi semakin genting. Penduduk berupaya memprovokasi petugas dengan perkataan yang bernada menghina. Selain itu, terdengar pula doa-doa dan ayat al-Qur'an dikumandangkan. Namun, massa berhasil ditenangkan. Entong Gendut sendiri belum mengambil tindakan untuk melawan, karena kekuatannya yang masih sangat terbatas. Akhirnya, rumah Taba dijual seharga $f$ 4,50 (4,50 gulden). Mandor Pirun membelinya pada tanggal 15 Maret 1916.
Situasi genting terus berkembang. Penduduk Batu Ampar bergabung dengan perkumpulan beladiri. Dengan ilmu bela diri yang dimiliki, mereka ingin mencegah para pegawai pemerintah mengeksekusi berbagai putusan pengadilan distrik.

Laporan yang sampai pada pemerintah menyebutkan bahwa Entong Gendut, Maliki, dan Modin yang berasal dari Batu Ampar memimpin perkumpulan tersebut. Selanjutnya, ditetapkan delapan wazir dan dua prajurit.

Anggota perkumpulan terus bertambah hingga mencapai sekitar 400 anggota. Bahkan sudah direncanakan merekrut pengikut hingga 1000 orang. Tokoh-tokoh setempat yang bergabung, antara lain Haji Amat Awab, Said Keramat dan Dullah. Haji Amat Wahab mengajarkan kitab "sifat 20". Haji Amat Wahab menunjukkan simpatinya pada Entong Gendut. Ia menasihati mandor Meli dari Kampung Tengah agar tidak mengikuti perintah Asisten Residen (ANRI, 1981: xl).

Derasnya dukungan terhadap gerakan Entong Gendut makin membuat perkumpulan ini muncul ke permukaan. Pemerintah mulai mencurigai aktivitas pengikut Entong Gendut. Asisten Wedana bahkan turun tangan menelusuri informasi sumir yang diperolehnya. Ia meminta keterangan pada Said Abdoellah, apakah turut terlibat dalam gerakan Entong Gendut. Said Abdoellah menyangkal, bahkan bersedia membantu mencari informasi yang lebih jelas mengenai keberadaan dan kegiatan Entong Gendut dan kelompoknya. Diberitakan pula beberapa orang keturunan Arab menjalin hubungan rahasia dengan perkumpulan itu. Di antara mereka ada Said Taba bin Akhmad Al Hadat dan Said Muksin bin Akhmad Alatas dari Cawang serta Said Umar bin Alaydrus dari Cililitan. Informasi mengenai keterlibatan orang Arab diperoleh berkat informan pemerintah yang bernama Said Abdullah (ANRI, 1981: xl). 
Insiden berikutnya berlangsung pada tanggal 5 April 1916. Pada sore harinya terjadi insiden. Pemilik tanah Tanjoeng Oost, D.C. Ament, dilempari dengan batu. Ketika itu mobilnya sedang melewati jembatan pal 13 dan 14 (ANRI, 1981: xl; Pranoto, 2010: 153). Kebencian penduduk pada tuan tanah semakin tak terbendung.

Pada malam harinya diadakan pertunjukan tarian topeng di Villa Nova milik Nyonya Van der Vasse Rollinson, pemilik tanah partikelir Cililitan Besar. Ketegangan pada sore hari rupanya terus berlanjut pada jam-jam berikutnya.

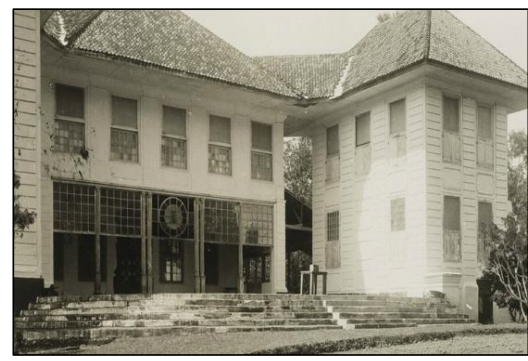

Gambar 2. Villa Nova tahun 1930

Sumber: arsipindonesia.com

Asisten Wedan memperoleh informasi dari polisi bahwa para pengikut Entong Gendut akan membubarkan pertunjukan topeng. Oleh karena itu, Asisten Residen beserta dua polisi mendatangi Villa Nova, yang sudah dijaga polisi pula (ANRI, 1981: xli).

Saat itu, segerombolan orang dipimpin Entong Gendut berkerumun di depan Villa Nova, rumah Lady Rollinson. Beberapa saat pertunjukan berlangsung tidak terjadi apa-apa. Hingga pukul 11.00, massa yang sudah berkumpul mulai menunjukkan kekesalan. Terdengar teriakan-teriakan "hentikan pertunjukan topeng". Teriakan-teriakan itu disertai dengan kumandang ayat-ayat Al-Qur'an. Seorang dari kerumunan massa yang bernama Madin berteriak "habib, habib". Habib merupakan sebutan bagi keturunan Nabi Muhammad saw. Entong Gendut mendesak agar pertunjukan dihentikan. Namun, Asisten Wedana berhasil membujuk Entong Gendut dan pengikutnya agar kembali ke rumah masing-masing. Sebelumnya Nyonya Rollinson menelepon komisaris polisi Mesteer Cornelis. Akan tetapi, dicegah Asisten Wedana yang lebih memilih langkah persuasif daripada represif. Dalam pandangan Asisten Wedana, saat ini yang diperlukan bukan tindakan mengirim polisi (ANRI, 1981: 54).

Entong Gendut memerintahkan orang-orang agar membubarkan diri dan kembali ke rumah masing-masing. Perintah Entong Gendut dipatuhi sehingga gerombolan bubar. Suasana kembali normal. Peristiwa ini berbuntut panjang. Entong Gendut masuk menjadi target buruan aparat keamanan Belanda di Batavia.

Mendengar kabar gerakan Entong Gendut yang semakin membahayakan, Wedana Meester Cornelis menugaskan Asisten wedana agar membawa Entong Gendut ke hadapannya. Upaya Asisten Wedana menangkap Entong Gendut gagal dilaksanakan, karena dihadang 50 pengikut Entong Gendut yang bersenjata lengkap. Sempat terjadi pembicaraan di antara Entong Gendut dengan Asisten Wedana. Jawara dari Condet itu memprotes mengapa para polisi yang merupakan orang pribumi malah membela orangorang Srani (orang-orang Belanda beragama Kristen). Mengapa pula polisi pribumi itu tega menyita, menjual bahkan membakar rumah sitaan. Gugatan Entong Gendut amat tajam. Dengan tegas, Asisten Wedana mengatakan bahwa ia hanya menjalankan tugas setelah dijatuhkannya vonis landraad. Sebagai hamba hukum, Asisten Wedana berkewajiban menegakkan tertib hukum.

Pada kesempatan itu Entong berupaya berargumentasi bahwa usahanya membubarkan pertunjukan topeng, karena ingin mencegah praktik perjudian sebagai ekses pertunjukan. Ia juga mengecam tradisi mabuk-mabukan para tuan tanah (ANRI, 1981: XLI, 54).

Pada tanggal 8 April ada kabar bahwa dukungan terhadap gerakan Entong 
Gendut terus bertambah. Salah satunya informasi dari Haji Sadan, penjaga gudang Nyonya Rollinson dan penjaga malam Villa Nova yang bernama Enceng. Anggota perkumpulannya semakin banyak. Entong Gendut menyatakan dirinya sebagai raja muda. Patihnya berjumlah delapan orang, yaitu Ja, Tipis, Raidi, Sibi bin Jimin, Logod, Tipe, Gutar dan Usep. Toha dan Gani dari Batuampar masingmasing menjadi mantri dan sekretaris. Anggota yang lain, Majar dan Jaimin, ditugaskan merekrut pengikut sebanyakbanyaknya (ANRI, 1981: XLI).

Gerakan Entong Gendut semakin mengancam pemerintah. Melalui surat yang dibawa Muhawa dari Kampung Cililitan Besar, Entong Gendut menyampaikan tantangan terbuka terhadap Asisten Wedana. Isi suratnya sebagai tercantum dalam berita acara Asisten Wedana Meester Cornelis (Raden Pringgodimedjo) tanggal 7 Maret 1916 sebagai berikut:

"Tjondet, Batoeampar 9 April 1916. Dengan hormat, Saya datang, dengan (Surat) ini untuk wedana (a sisten wedana) Mantri dan aparat polisi. Saya berharap bahwa semua yang mengikuti ajaran Nabi Muhammad baik laki-laki maupun perempuan di Onderdistrik Tandjong Pasar Rebo dapat diberitahukan agar berkumpul di rumah Raja Muda yang bernama Tong Gendut. Jika wedana (asisten wedana) sendiri tidak datang ke rumah Raja Muda. Berhati-hatilah, karena begitu banyak orang yang akan datang bertemu Raja Muda. Untuk (Anda) sebagai peringatan: Ini sangat mendesak dan Anda perlu untuk datang besok pagi jam 8. Jika tidak wedana Pasar Rebo?"

Muhawa setelah menyampaikan surat, langsung meloloskan diri. Ia menyadari bahwa bahaya sedang mengintainya. Terlebih bila ia harus membocorkan rahasia kelompok Entong Gendut (ANRI, 1981: 52).

Pemerintah kolonial segera melakukan operasi penangkapan Entong Gendut. Pada tengah malam antara tanggal 9 dan 10 April 1916 rumah Entong Gendut dikepung. Pihak keamanan yang dipimpin Wedana berusaha menangkapnya hidup atau mati.

Saat itu Entong Gendut sedang sholat. Selesai sholat, berlangsung negosiasi antara dua pihak. Entong Gendut keluar dari dalam rumah. Dibawanya benda panjang yang dibungkus kain putih (semacam tombak), beberapa keris dan bendera merah dengan gambar bulan sabit berwarna putih di tengah-tengah (ANRI, 1981: xliii).

Wedana memberi tahu bahwa ia akan menangkap Entong Gendut. Dengan rasa percaya diri yang tinggi ia berkata dengan lantang bahwa dirinya adalah raja muda (Ik ben Radja Moeda) . Oleh karena itu, ia tidak perlu tunduk kepada siapa pun, termasuk hukum kolonial. Ia juga menegaskan siap berjihad fi sabilillah melawan polisi (wil de sabiloellah (godsdienstoorlog) met de politie uitvechten) (ANRI, 1981: 59).

Entong Gendut bahkan turun ke halaman sambil membaca mantra dan menampilkan silat. Ketika Wedana memberi aba-aba penangkapan, Entong Gendut berteriak, "Anak-anak". kemudian, gerombolan orang bersenjata keluar dari semak-semak kebun salak dan langsung mengepung petugas pemerintah. Jumlahnya 200 orang bersenjata (ANRI, 1981: xliii).

Polisi yang bernama Salim dan Atjim berupaya menangkap pengikut Entong Gendut. Namun, Saadi dari Kampung Tengah melayangkan parang ke kepala salim. Polisi melihat jimat-jimat di tubuh pengikut Entong Gendut (ANRI, 1981: 59). Keadaan semakin mencekam. Massa bersiap untuk berperang.

Mereka mengepung rombongan Wedana dan polisi kampung dari berbagai penjuru. Menyadari bahaya yang mengancam dirinya, Wedana dan rombongannya berlarian menyelamatkan diri. Wedana yang bersembunyi di rumah kosong berhasil ditangkap massa. Untunglah nasib baik berpihak pada wedana. Begitu ditanya bahwa wedana juga seorang muslim, Entong Gendut tidak 
jadi membunuhnya. Ia hanya melakukan penawanan atas diri wedana di rumah kakak Entong Gendut. Para pengikut menjaga rumah dengan ketat.

Pada pukul 02.00 dini hari Asisten Wedana mendengar berita penawanan Wedana dan penangkapan Entong Gendut yang gagal. Oleh karena itu, Asisten Wedana meminta tambahan polisi dan dukungan militer. Balabantuan pasukan pemerintah tiba pada pukul 04.00 pagi.

Pasukan bantuan yang dipimpin Asisten Residen langsung bergerak menuju tempat wedana ditawan. Ikut serta dalam rombongan tersebut Asisten Wedana Pasar Rebo dan pembesar polisi.

Terjadilah pertempuran sengit. Saat itu juga Wedana dilepaskan. Para pengikut Entong Gendut melontarkan teriakan, "Sabilillah tidak takut!" dan "Allahu Akbar". Massa pengikut Entong Gendut terus berdatangan. Mereka mengibasibaskan bendera merah sambil memainkan gerakan-gerakan ilmu silat. Pasukan pemerintah mencoba memberi peringatan agar massa mundur. Rupanya hal tersebut tidak digubris. Kemudian pasukan pemerintah menembaki massa secara brutal. Pengikut Entong Gendut pontangpanting menyelamatkan diri ke kampung. Di kampung terdengar suara tembakan dan bedug bertalu-talu tanda bahaya.

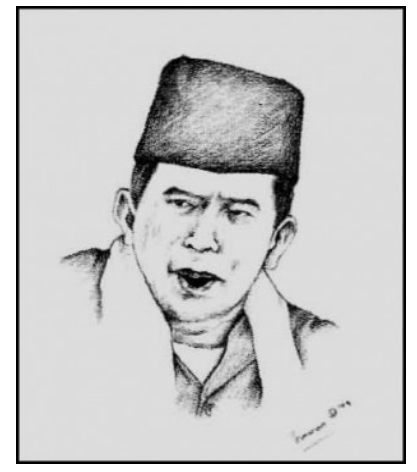

Gambar 2. Lukisan Wajah Entong Gendut Sumber: http://www.jakarta.go.id/ web/encyclopedia

Menurut laporan berita acara Asisten Wedana Pasar Rebo tanggal 17
April 1916, pasukan pemerintah berhasil menembak Entong Gendut. Ia mengalami luka yang parah dan meninggal dalam perjalanan ke rumah sakit. Bahkan mengenai kematian Entong Gendut terdapat beberapa versi. ada yang menyebut ia meninggal di Batuampar, saat melewati sungai ketika dikejar polisi pemerintah. Ada yang mengatakan jenazah Entong Gendut diceburkan ke laut. Ada bermacam-macam versi mengenai makam Entong Gendut. ada yang mengatakan di Kemang, ada pula di Kampung Wadas, Bogor. Entong Gendut meninggalkan tiga anak, yaitu Abdul Fikor, Aiyoso, dan Aisyah. $^{3}$

Para pengikutnya yang tertembak dibawa ke rumah sakit. Tidak lama kemudian, bantuan militer tiba dan berjaga-jaga di jalan raya untuk mengantisipasi kerusuhan yang lebih luas (ANRI, 1981: XLIV).

Pada hari Senin tanggal 10 April pukul 9.00 pagi pemberontakan sudah berakhir. Tidak ada lagi suara tembakan dan bedug. Pasukan pemerintah menyerbu kampung. Mereka menggeledah setiap rumah. Para lelaki digiring keluar rumah. Mereka dikumpulkan dan ditawan. Pemerintah mendapat berita bahwa para lelaki di kampung sudah menjadi pengikut Entong Gendut. Ternyata di antara para tawanan banyak yang mengenakan jimat seperti yang dipakai pengikut Entong Gendut (ANRI, 1981: xliv).

Kematian Entong Gendut dan ditawannya para pengikutnya itu mengakiri episode perlawanan petani di tanah partikelir Tanjoeng Oost.

Berdasarkan laporan Asisten Residen Meester Cornelis (D. Heyting) kepada Residen Batavia (H. Rijsnijder) tanggal 18 April 1916 ada pengakuan Entong Gendut bahwa perlawanannya dilatarbelakangi oleh rasa belas kasihan terhadap penduduk. Rakyat yang tidak

\footnotetext{
${ }^{3}$ (http://www.jakarta.go.id/web/encyclopedia/d etail/518/Entong-Gendut), diunduh 16 Januari 2015 pukul 8.49 WIB.
} 
berdosa rumahnya dibakar, karena gagal bayar.

Penduduk yang gagal bayar jumlahnya semakin bertambah. Di tanah partikelir Tandjoeng Timur dan Tjiboeboer pada tahun 1913 total sekitar 2.000 kasus yang dieksekusi. Pada 1911 ada \pm 500 dan $1915 \pm 300$ kasus kegagalan membayar sewa kebun dan penebusan pembayaran untuk heerendiensten. Eksekusi sudah dilakukan terhadap 20 rumah yang dijual dan tujuh dibongkar.

Kelompok Entong Gendut mengecam cara-cara pemerintah dalam mengeksekusi kegagalan penduduk mengikuti ketentuan dari tuan tanah (ANRI, 1981: xlii).

Sementara itu, bagi tuan tanah, ketentuan pajak dan kerja wajib yang diterapkan pada penduduk amatlah menguntungkan. Uang sewa tanah pekarangan dan pengganti kerja wajib mengisi pundi-pundi kekayaan tuan tanah. Para tuan tanah dapat sesuka hatinya untuk menentukan besar pungutan sehingga sering berubah-ubah. Penduduk-penyewa tidak dapat menolak karena mereka tinggal di atas tanah milik tuan-tanah (ANRI, 1981: XLII).

Pemerintah sebenarnya bukan tidak peduli dengan kondisi penduduk di tanah partikelir Tanjoeng Oost. Pungutan yang nilainya terus berubah-ubah memang menjadi permasalahan serius bagi penduduk. Oleh karena itu, Asisten Residen mengusulkan agar pemerintah membeli kembali tanah-tanah yang dikuasai pihak swasta. Selain itu, perlu adanya patokan besaran pungutan yang pasti seperti tanah-tanah di gubernemen. Dengan demikian, ada kepastian standar pungutan selama beberapa tahun ke depan. Bila ada kenaikan, maka dilakukan secara bertahap sehingga tidak memberatkan penduduk (ANRI, 1981: xlii).

Kritik dan protes terhadap praktik eksploitasi mulai mencuat. Akhirnya Pemerintah Hindia Belanda mengeluarkan besluit tanggal 16 Maret 1920 No. 3. Isi dari besluit tersebut, pemerintah membentuk suatu komisi di bawah pimpinan Mr. K.F. Creutzberg yang bertugas melakukan penyelidikan lebih mendalam mengenai soal-soal tanah partikelir. Sebagai tindak lanjut dari penyelidikan tersebut dikeluarkan Keputusan Kerajaan Belanda tanggal 12 Agustus No. 51 (Stbl No. 480 tahun 1921) mengenai "Keputusan tentang pembelian kembali tanah-tanah partikelir di Hindia Belanda menjadi tanah negara". Pemerintah, bahkan, membentuk kantor yang ditugaskan untuk mengurus bekas tanah partikelir. Pada tahun 1931, kantor tersebut dirampingkan hingga tahun 1932 hanya mempunyai 2 orang pejabat. Kedua pejabat tersebut menentukan pemberian tanah kongsi, mengurus soal perselisihan tanah, dan membuat laporan. Kantor tersebut dihapuskan sama sekali tahun 1934. Urusan tanah partikelir diserahkan pada pangreh praja ANRI, 1980: cxxi).

Memang, dalam merespons persoalan di tanah partikelir, pihak pemerintah menunjukkan keberpihakan setengah hati. Misalnya, dalam memorie Residen Batavia (J.D. Hunger) 3 Maret 1922, ada catatan tentang masalah di tanah partikelir. Residen mengkritik opini-opini yang beredar di Dewan Rakyat yang menyebutkan bahwa penghapusan pungutan dan kewajiban akan memperbaiki kesejahteraan penduduk. Residen menilai hal tersebut tidak tepat. Melepaskan pungutan dan kewajiban kerja penduduk di tanah partikelir sama artinya menelantarkan tanah menjadi lahan tidak produktif. Tidak ada pemasukan bagi tuan tanah. Oleh karena itu, residen berpendapat pembelian tanah partikelir oleh pemerintah atau pencabutan hak menjadi solusi yang lebih masuk akal (ANRI, 1976: xxxi).

Pemerintah dan Dewan Rakyat memang tidak diizinkan untuk campur tangan dalam urusan di tanah partikelir meski para petani sering mengeluhkan beratnya pungutan. Pemerintah dan Dewan Kota hanya bisa mengutuk buruknya kehidupan di tanah partikelir (Blackburn, 166). Ketentuan hukum yang dibuat 
memang jadi permasalahan tersendiri bagi pemerintah. Pada tanggal 28 Februari 1836 diumumkan Publicatie (Staatsblad No. 19) yang mengatur tanah partikelir di sebelah barat sungai Cimanuk. Isi dari staatsblad tersebut kurang lebih menyatakan bahwa pemerintah tidak dapat melakukan intervensi terhadap urusan pemerintahan di tanah partikelir. Para kepala kampung di wilayah tanah partikelir tidak dipilih seperti kebiasaan di Jawa pada umumnya, melainkan diangkat oleh tuan-tuan tanah. Oleh karena itu, tentu saja kepala kampung lebih mementingkan tuan tanah daripada kepentingan penduduk (ANRI, 1973: lix).

\section{Analisis Gerakan}

Perubahan sosial akibat kebijakan kolonial telah menimbulkan diferensiasi struktur dalam masyarakat pedesaan. Kehidupan organisasi desa yang lepas di tanah partikelir membuat kedudukan tuan tanah menjadi lebih kuat. Tuan tanah menjadi kelompok yang mendominasi dengan petani menjadi subordinasi. Dalam sistem yang timpang itu, muncul keresahan dalam bentuk protes sosial.

Di tanah partikelir terbangun stratifikasi sosial secara hirarkis. Pemilik tanah bergabung dengan elit birokrasi pribumi menempati lapisan sosial atas.

Sementara itu, penduduk lainnya yang terdiri dari elite kampung diduduki oleh pemimpin agama, antara lain haji, kiai, dan unsur nonbirokrat. Mereka juga berperan sebagai counter-elite. Penduduk kampung menduduki posisi paling bawah, yaitu petani yang dapat dirinci lagi dalam petani biasa, petani penggarap, dan buruh tani.

Hubungan antara Entong Gendut dan para pengikutnya lekat dengan pola ketergantungan dan saling membutuhkan atau patron klien. Bahkan dimensi keagamaan nampak dengan jelas. Dalam berbagai kesempatan, mereka menegaskan identitas dengan membaca ayat-ayat alQur'an. Selain itu, ide perang sabil amat kuat mewarnai gerakan Entong Gendut.

Petani harus menanggung beban yang berat di tanah partikelir Tanjoeng
Oost. Tuan tanah memiliki hak menarik pajak (tjuke) dan layanan (tenaga kerja) dari para petani. Tumbuhnya solidaritas yang sama menguatkan dorongan untuk melakukan gerakan sosial. Ketidakadilan dan kemiskinan menjadi isu utama perlawanan petani di Condet, Tanjoeng Oost. Kesewenang-wenangan tuan tanah melepaskan hak petani atas tanah dan rumah.

Faktor pencetus adalah sesuatu yang dramatis dan bermula dari hal-hal yang biasa. Pertunjukan yang dibarengi dengan perkelahian menjadi pemicu yang mudah meledak. Kuatnya pengaruh para jawara banyak diakibatkan lemahnya wibawa para pejabat baru yang dilantik sesudah reorganisasi 1908. Berbeda dengan kawasan lainnya, di tanah Batavia tidak ada penguasa-penguasa tradisional, seperti raja, bupati, atau pun kepala desa adat (ANRI, 1981: xxv).

Mobilisasi massa memerlukan tokoh yang menjadi pemersatu sekaligus penggeraknya. Entong Gendut menjadi magnet yang menghimpun penduduk agar menentang tuan tanah. Protes yang dilakukan petani sering berakhir dengan penangkapan terhadap tokoh dan pengikutnya. Begitu tokoh yang kharismatis tertangkap atau tewas, berakhirlah perlawanan petani.

Perlawanan kaum tani tidak sematamata dipengaruhi situasi internal kehidupan mereka sehari-hari. Mereka berada dalam jejaring sistem yang lebih besar. Oleh karena itu, sebagai akibat dari polarisasi lingkungan pedesaan setelah adanya komersialisasi mengakibatkan distribusi pemilikan tanah hanya tertuju pada pemilik modal. Tuan tanah memandang petani sebagai faktor produksi yang murah, bahkan barang yang memungkinkan baginya meningkatkan kekayaan dan kekuasaannya. Itulah sebabnya petani sering dianggap sebagai sumber masalah. Dengan kata lain, mereka dituduh sebagai basis konflik di lingkungan tanah partikelir. 
Gerakan Entong Gendut bersifat sangat sporadis dan reaktif sehingga dapat dipatahkan dengan mudah. Hal tersebut berbeda dengan masa-masa sesudah lahirnya Sarekat Islam yang lebih terorganisir. Isu-isu mengenai kemiskinan di tanah partikelir dikemas sedemikian rupa sehingga tuntutan radikal agar pemerintah melakukan reformasi. Misalnya, SI mengeritik kehidupan di tanah partikelir Kwitang-Oost dan Kemayoran (Blackburn, 2011: 146).

Meluasnya sistem ekonomi uang telah melumpuhkan kehidupan petani. Kemiskinan mengakibatkan meningkatnya angka kejahatan. Aksi kriminalitas dapat dipandang sebagai protes sosial yang tidak terorganisasi. Entong Gendut dan para pengikutnya berupaya mengembalikan hak para petani akibat sistem pajak dan kebijakan tidak adil pemerintah kolonial dan tuan tanah.

Dari perspektif pribumi, Entong Gendut adalah pahlawan yang mencoba membebaskan petani dari belenggu ketidakadilan dan penindasan tuan tanah. Sebaliknya, pandangan kolonial menganggap Entong Gendut sebagai kriminal yang mengganggu tatanan kolonial.

Membaca gerakan Entong Gendut mesti diletakkan dalam bingkai perbanditan sosial. Peranan kelompok bandit sosial merupakan counter-elite yang bergerak di bawah tanah sehingga merupakan ancaman latent bagi yang sedang berkuasa. Seseorang menjadi bandit karena ia melakukan sesuatu yang oleh adat kebiasaan di daerahnya tidak dianggap sebagai tindakan kejahatan, melainkan negaralah atau penguasa setempat yang menganggapnya demikian (Hobsbawn, 1984: 76). Dalam pandangan masyarakat, bandit dianggap sebagai pahlawan. Sebaliknya, di mata penguasa bandit dipandang sebagai pembangkang yang membahayakan.

Fenomena kehidupan bandit mencirikan tipikal pola pedesaan dan bukan perkotaan. Dalam stratikasi sosial masyarakat petani ada pembedaan yang tegas antara golongan kaya dan miskin, golongan kuat dan golongan lemah, golongan pemerintah dan yang diperintah. Kehidupan bandit tumbuh dan berkembang dalam kehidupan prakapitalis (Hobsbawn, 1984 : 85). Entong Gendut dan pengikutnya melawan "tertib hukum" dengan hukum versi mereka sendiri.

\section{PENUTUP}

Protes sosial yang melanda tanah partikelir Tanjoeng Oost Batavia merefleksikan adanya ketegangan vertikal antar rakyat dengan penguasa. Protes tersebut merupakan respons masyarakat petani terhadap perubahan yang terjadi di lingkungannya akibat praktik komersialisasi dan kapitalisasi.

Dominasi pemerintah kolonial telah menggoyahkan tatanan masyarakat tradisional dan nilai-nilainya. Ekonomi uang dan faktor-faktor produksi memungkinkan diterapkannya sistem pajak oleh pemerintah kolonial. Pajak menjadi beban yang memberatkan petani. Selain itu, mereka harus melaksanakan kerja wajib tanpa kecuali.

Protes sosial yang terjadi di tanah partikelir Tanjoeng Oost bernuansa quasirelijius. Entong Gendut dianggap masyarakat sebagai Ratu Adil yang akan membawa pada kebebasan dan kejayaan.

Protes sosial di tanah partikelir Tanjoeng Oost dapat menjadi pelajaran bagi semua pihak, khususnya penyelenggara negara. Perlawanan kaum lemah tidak saja ditunjukkan dengan aksi kekerasan, tetapi juga dalam bentuk lain, ketidaktaatan, tidak tertib, kualitas kerja yang buruk, dan lain-lain. Semuanya itu tentu saja bila dikaitkan dalam konteks pembangunan justru dapat menghambat kemajuan. Oleh karena itu, kehidupan sosial dalam berbagai tatarannya harus dibangun dalam prinsip kesamaan dan keadilan. Kebijakan yang berpihak pada "arus bawah" harus menjadi pilihan yang jelas dan tegas. 


\section{DAFTAR SUMBER}

\section{Arsip}

Indonesia. Arsip Nasional. 1973.

Ikhtisar Keadaan Politik Hindia Belanda tahun 1839-1848. Jakarta: ANRI.

Indonesia. Arsip Nasional. 1976.

Memori Serah Jabatan 1921-1930

(Jawa Barat). Jakarta: ANRI.

Indonesia. Arsip Nasional. 1980.

Memori Serah Jabatan 1931-1940

(Jawa Barat). Jakarta: ANRI.

Indonesia. Arsip Nasional. 1981.

Laporan-laporan tentang Gerakan Protes di Jawa pada Abad XX. Jakarta: ANRI.

Koloniaal Verslag, 1916

\section{Skripsi}

Nashir, Abd. 1987.

Kerusuhan Petani di Condet Tahun 1916. Skripsi. Depok: Fakultas Ilmu Pengetahuan Budaya UI.

Ningsih, Yayi. 1987.

Gerakan Protes di Tanjung Timur Dipimpin oleh Entong Gendut Tahun 1916. Skripsi. Surabaya: FIS UNESA.

\section{Buku}

Asdi, Armin et al. 2007.

Sejarah Kabupaten Subang. Subang: Disbudpar Kab. Subang.

Burke, Peter. 2003.

Sejarah dan Teori Sosial. Jakarta: Yayasan Obor Indonesia.

Effendhie.

"Korupsi dan Kolusi pada Masa Raffles" dalam Humaniora Vol. 19 No. 1. Februari 2007. Hlm. 13-22.

Frederick, William \& Soeri Soeroto. 1984. Pemahaman Sejarah Indonesia Sebelum dan Sesudah Revolusi. Jakarta: LP3ES.

Herlina-Lubis, Nina. 2000.

Tradisi \& Transformasi Sejarah Sunda. Bandung: Humaniora Utam Press.

Hobsbawn, E.J., 1990.

"Bandit Sosial", dalam Sartono
Kartodirdjo, Kepemimpinan dalam Dimensi Sosial, Jakarta : LP3ES.

Blackburn, Susan. 2011.

Jakarta Sejarah 400 tahun. Depok: Komunitas Bambu.

Hoffer, Eric. 1988.

Gerakan Massa. Jakarta: Yayasan Obor Indonesia.

Ishwara, Luwi. 2011. Jurnalisme Dasar. Jakarta: Kompas.

Jung, Richard, "A Review of Theory of Collective Behavior Neil J. Smelser", Industrial and Labor Relations Review, 19, 2 (January 1966). P. 318-320.

Kartodirdjo,Sartono. 1983.

Elit dalam Perspektif Sejarah. Jakarta: LP3ES.

Korver, A.P.E. 1982. Sarekat Islam Gerakan Ratu Adil?. Jakarta: Grafiti Pers.

Poesponegoro, Marwati Djoened dan Nugroho Notosusanto. 2008.

Sejarah Nasional Indonesia IV: Kemunculan Penjajahan di Indonesia. Jakarta: Balai Pustaka.

Pranoto, Suhartono W. Jawa (Bandit-bandit Pedesaan) Studi Historis 1850-1942. Yogyakarta: Graha Ilmu.

Scott, James C. 1993.

Perlawanan Kaum Tani. Jakarta: Yayasan Obor Indonesia.

Surbakti, Ramlan. 2010. Memahami Ilmu Politik. Jakarta: Grasindo.

Zubir, Zaiyardam. 2002. Radikalisme kaum Pinggiran. Yogyakarta: Insist.

\section{Internet}

Scott, James C. "Patron-Client Politics and Political Change in Southeast Asia", diakses dari http://chenry.webhost. utexas. edu/public_html/AUC/Scott1972-clientelism.pdf, diunduh pada 10 Februari 2015 pukul 8.45 WIB.

Swartz, Norman. "The Concepts of Necessary and Sufficient Conditions", diakses dari http://www.ucd.ie/artspgs/semantics/sw artznsc.pdf, diunduh pada 24 Februari 2015 pukul 9.03 WIB. 